\title{
Body mass index and mortality in patients with gastric cancer: a large cohort study
}

\author{
Jung Hwan Lee ${ }^{1}$ Boram Park ${ }^{2}$ Jungnam Joo ${ }^{2} \cdot$ Myeong-Cherl Kook ${ }^{1}$. Young-II Kim ${ }^{1}$. Jong Yeul Lee ${ }^{1}$. \\ Chan Gyoo Kim ${ }^{1} \cdot$ II Ju Choi ${ }^{1} \cdot$ Bang Wool Eom ${ }^{1} \cdot$ Hong Man Yoon ${ }^{1} \cdot$ Keun Won Ryu ${ }^{1} \cdot$ Young-Woo Kim ${ }^{1}$. \\ Soo-Jeong $\mathrm{Cho}^{1}{ }^{10}$
}

Received: 11 January 2018 / Accepted: 7 March 2018 / Published online: 12 April 2018

(c) The International Gastric Cancer Association and The Japanese Gastric Cancer Association 2018

\begin{abstract}
Background The effects of obesity on prognosis in gastric cancer are controversial.

Aims To evaluate the association between body mass index (BMI) and mortality in patients with gastric cancer.

Methods A single-institution cohort of 7765 patients with gastric cancer undergoing curative gastrectomy between October 2000 and June 2016 was categorized into six groups based on BMI: underweight $\left(<18.5 \mathrm{~kg} / \mathrm{m}^{2}\right)$, normal $(18.5$ to $<23 \mathrm{~kg} /$ $\mathrm{m}^{2}$ ), overweight $\left(23\right.$ to $\left.<25 \mathrm{~kg} / \mathrm{m}^{2}\right)$, mildly obese $\left(25\right.$ to $\left.<28 \mathrm{~kg} / \mathrm{m}^{2}\right)$, moderately obese $\left(28\right.$ to $\left.<30 \mathrm{~kg} / \mathrm{m}^{2}\right)$, and severely obese $\left(\geq 30 \mathrm{~kg} / \mathrm{m}^{2}\right.$ ). Hazard ratios (HRs) for overall survival (OS) and disease-specific survival (DSS) were calculated using Cox proportional hazard models.

Results We identified 1279 (16.5\%) all-cause and 763 (9.8\%) disease-specific deaths among 7765 patients over 83.05 months (range 1.02-186.97) median follow-up. In multivariable analyses adjusted for statistically significant clinicopathological characteristics, preoperative BMI was associated with OS in a non-linear pattern. Compared with normal-weight patients, underweight patients had worse OS [HR 1.42; 95\% confidence interval (CI) 1.15-1.77], whereas overweight (HR 0.84; 95\% CI $0.73-0.97$ ), mildly obese (HR 0.77 ; 95\% CI 0.66-0.90), and moderately obese (HR 0.77 ; 95\% CI 0.59-1.01) patients had better OS. DSS exhibited a similar pattern, with lowest mortality in moderately obese patients (HR 0.58 ; 95\% CI 0.39-0.85). Spline analysis showed the lowest all-cause mortality risk at a BMI of $26.67 \mathrm{~kg} / \mathrm{m}^{2}$.

Conclusion In patients undergoing curative gastric cancer surgery, those who were overweight or mildly-to-moderately obese (BMI 23 to $<30 \mathrm{~kg} / \mathrm{m}^{2}$ ) preoperatively had better OS and DSS than normal-weight patients.
\end{abstract}

Keywords Body mass index $\cdot$ Gastric cancer $\cdot$ Mortality $\cdot$ Obesity $\cdot$ Gastrectomy

Jung Hwan Lee and Boram Park have contributed equally to this work.

Electronic supplementary material The online version of this article (https://doi.org/10.1007/s10120-018-0818-x) contains supplementary material, which is available to authorized users.

Jungnam Joo jooj@ncc.re.kr

$\triangle$ Soo-Jeong Cho crysta1522@daum.net; crystal522@ncc.re.kr

1 Center for Gastric Cancer, National Cancer Center, 323 Ilsan-ro, Ilsandong-gu Goyang, Gyeonggi 10408, Republic of Korea

2 Biometrics Research Branch, Research Institute, National Cancer Center, 323 Ilsan-ro, Ilsandong-gu Goyang, Gyeonggi 10408, Republic of Korea

\section{Introduction}

Gastric cancer is the fourth most common malignancy and the third leading cause of cancer-related death [1]. For the past 20 years, survival has improved significantly because of several factors, including early detection, more skillful surgical treatment, improved nutritional care, and widespread use of systemic chemotherapy [2]. However, it is not yet clear whether or how obesity is related to prognosis in patients with gastric cancer.

Obesity is an undisputed risk factor for the development of several cancers [3]. Endometrial cancer, for example, has been strongly associated with an increased body mass index (BMI) [4]. However, the association between BMI and some cancers, including gastric cancer, is weak or uncertain [5]. Two independent meta-analyses about the relationship 
between BMI and the incidence of gastric cancer reported conflicting conclusions [5, 6]. Tumor location appears to play a role, as obesity may be associated with cardia gastric cancers but not non-cardia cancers [6-9].

Interestingly, some studies reported that obesity at diagnosis improves survival in cancer patients. This "obesity paradox" has been observed primarily in renal cell $[10,11]$ and colorectal cancers [12-14]. Among patients who underwent gastric resection for gastric cancer, outcomes seemed to be better in patients with a high BMI than in patients with a normal or low BMI $[15,16]$. However, the previous studies compared patients using only the criteria of a BMI above $25 \mathrm{~kg} / \mathrm{m}^{2}$, which is inappropriate for the Asian population [17], or the sample size of these studies was relatively small for conducting comprehensive subgroup analyses according to tumor stage.

In the present study, we used data from a prospectively collected data set of $>7000$ patients with primary gastric cancer undergoing curative gastrectomy to retrospectively perform robust, comprehensive subgroup analyses to determine whether BMI at diagnosis is associated with patient survival during a median follow-up of $>80$ months.

\section{Methods}

\section{Patients}

This retrospective study was conducted at the National Cancer Center (Korea) and used a prospectively collected data set of consecutive patients. A total of 9173 consecutive patients underwent gastrectomy from December 2000 to June 2016 at the Center for Gastric Cancer at National Cancer Center. We excluded 310 patients, because they had benign neoplasms $(n=72)$ or a malignancy other than adenocarcinoma (e.g., squamous cell carcinoma, neuroendocrine carcinoma, gastrointestinal stromal tumors, and lymphoma; $n=238$ ). Moreover, 916 patients were further excluded, because they had recurrent cancers $(n=137)$, neoadjuvant chemotherapy $(n=21)$, stage IV cancer $(n=630)$, or $\mathrm{R} 1$ or $\mathrm{R} 2$ resections $(n=128)$. Of the remaining 7947 patients undergoing curative gastrectomy for primary gastric adenocarcinoma, 158 were lost to follow-up and 22 died within 1 month after surgery (these were considered postoperative deaths, representing hospital mortality). In two patients, the BMI at diagnosis was missing. Finally, 7765 patients were enrolled in this study (Fig. 1). The institutional review board of the National Cancer Center, Korea, approved this study (NCC2017-0046).

BMI was calculated as weight divided by height squared $\left(\mathrm{kg} / \mathrm{m}^{2}\right)$. BMI was classified into six categories reflecting the International World Health Organization (WHO) criteria and revised WHO criteria for Asian populations [17, 18]: normal-weight, 18.5 to $<23 \mathrm{~kg} / \mathrm{m}^{2}$; underweight, $<18.5 \mathrm{~kg} /$ $\mathrm{m}^{2 .}$; overweight, 23 to $<25 \mathrm{~kg} / \mathrm{m}^{2}$; mildly obese, 25 to $<28 \mathrm{~kg} / \mathrm{m}^{2}$; moderately obese, 28 to $<30 \mathrm{~kg} / \mathrm{m}^{2}$; and severely obese, $\geq 30 \mathrm{~kg} / \mathrm{m}^{2}$.

Patient follow-up continued until death or the study cutoff date of June 30, 2016. Median follow-up duration was 83.05 months (range 1.02-186.97 months). Post-operatively, follow-up endoscopy was performed at 3, 6, and 12 months and then annually to detect local recurrence or another primary lesion. To detect lymph node and distant metastases, abdominal computed tomography was performed 6 months post-operatively and then annually.

Most patients undergoing gastrectomy experienced weight loss. To assess the effect of weight change, postoperative BMI at 1 year was determined for patients enrolled in 2010-2012 $(n=1765)$. One-year post-operative BMI was the weight measured between 9 and 15 months after surgery. Post-operative BMI tends to be maintained after 12 months regardless of the type of operation [19].

Considering other factors possibly affecting survival, we collected other patient data: age, sex, lifestyle, comorbidity, family history of gastric cancer, operation method, WHO histological classification, tumor size, tumor location, TNM stage, and adjuvant chemotherapy. Family history was defined as a first-degree relative with gastric cancer. Smoking was categorized as former or current smoker. Cumulative smoking amount was calculated in pack-years, assuming that one pack contained 20 cigarettes. Drinking was judged as present or absent. Gastric cancer staging was defined according to the 7th Edition of the American Joint Committee for Cancer [20]. The Lauren classification was excluded, because we considered detailed WHO histology as a covariate. Tumor location was divided into proximal third (fundus, cardia, and high body), middle third (midbody, lower body, and angle), and lower third (antrum and pylorus). Location was classified as "extended" when the cancer invaded $>2$ sections. Cancer size was the longest diameter in the pathology results.

American Society of Anesthesiologists (ASA) score was used as an indicator of comorbidity. It is a subjective assessment of overall health, divided into five classes [21]: I, completely healthy and fit; II, mild systemic disease; III, severe systemic disease, which is not incapacitating; IV, incapacitating disease that is a constant threat to life; and $\mathrm{V}$, moribund and expected to die within $24 \mathrm{~h}$ (with or without surgery). No level V patient was included. Complications included immediate events during hospitalization and delayed events after discharge.

\section{Surgery and adjuvant chemotherapy}

All patients underwent open or laparoscopy-assisted total or subtotal gastrectomy with D1+ or D2 lymphadenectomy 


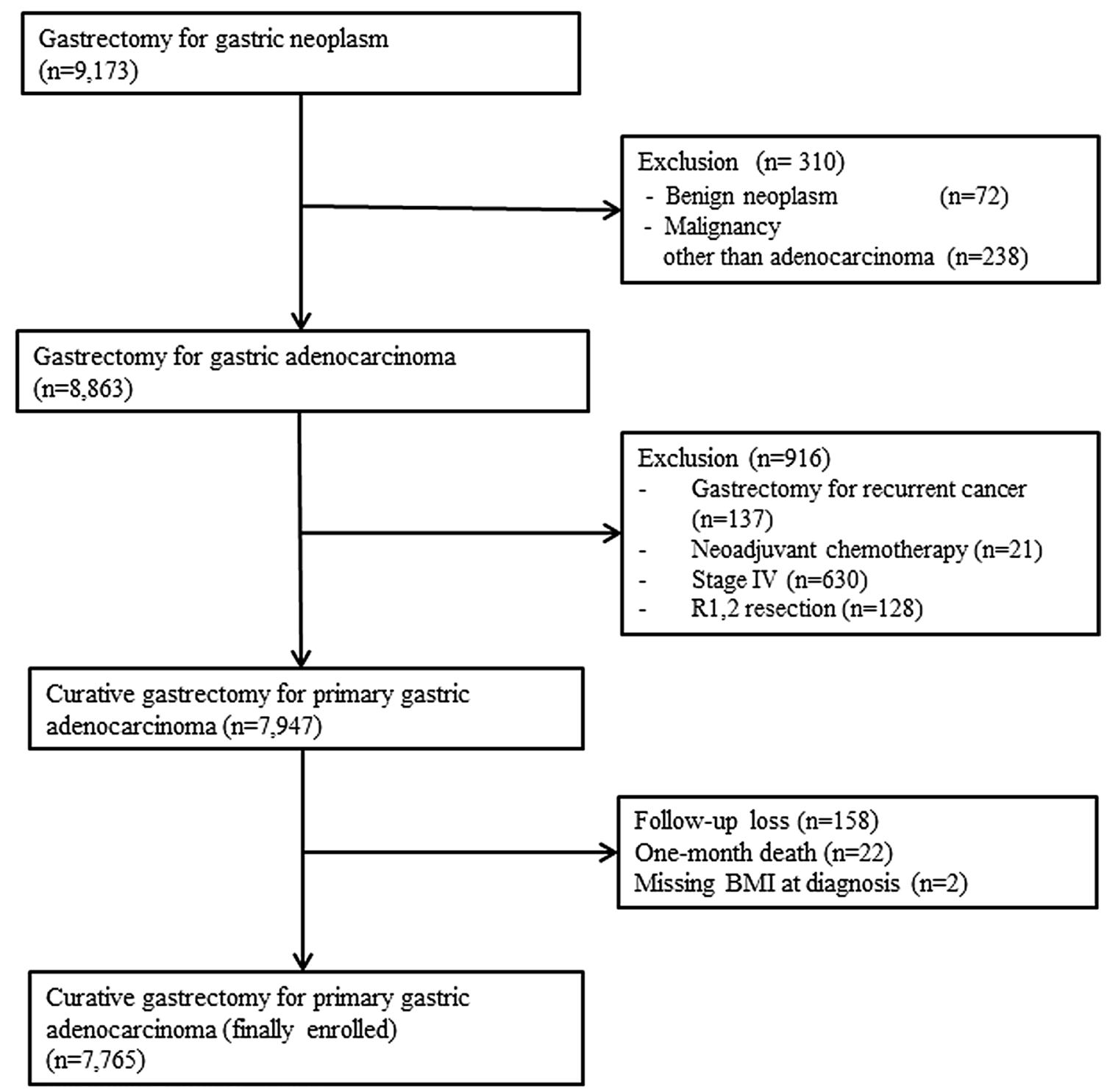

Fig. 1 Flow chart of included patients with gastric cancer who underwent curative resection. $B M I$ body mass index

[22]. Total or subtotal gastrectomy was based on tumor size and location, status of resection margin, and lymph node involvement. Since 2012, functional preserving gastrectomy, such as proximal gastrectomy, pylorus-preserving gastrectomy, or wedge resection, was also performed based on tumor characteristics. Patients undergoing wedge resection were recruited for a phase III clinical trial [SEntinel Node ORIented Tailored Approach (SENORITA) trial] [23, 24]. Curative resection was confirmed in all patients, based on the Japanese guideline definition: no peritoneal or distant metastasis and negative peritoneal fluid cytology [25]. Adjuvant chemotherapy was determined by patient age and performance status, as well as tumor stage. The regimens included 5-fluorouracil/cisplatin, capecitabine/oxaliplatin, tegafur, or tegafur/cisplatin.

\section{Statistical analysis}

Baseline characteristics were described according to the $6 \mathrm{BMI}$ groups. Continuous variables were summarized as mean \pm standard deviation and analyzed using one-way analysis of variance. For categorical variables, frequency and percentage were determined, and differences in distribution were estimated using Pearson's Chi-square test. Overall survival (OS) was determined from surgery until death from any cause. Disease-specific survival (DSS) was determined from surgery to death due to gastric cancer. Survival curves were derived using the Kaplan-Meier method, and statistical differences between BMI groups were evaluated using the log-rank test. To investigate associations between BMI and gastric cancer mortality, hazard ratios (HRs) and 95\% 
confidence intervals (CIs) were calculated using Cox proportional hazards models. In multivariable Cox proportional hazards models, statistically significant factors were adjusted for among these 12 factors: age, sex, current smoker, alcohol use, family history of gastric cancer, operation, tumor histology, tumor size, adjuvant chemotherapy, TNM stage, location, and ASA score. We also performed subgroup analyses based on age ( $<40$ vs. $\geq 40$ to $<65$ vs. $\geq 65$ ), TNM stage, and operation method. When subgroup analyses were performed, age, sex, and TNM stage were adjusted for in multivariable analysis. To account for the possibility of reverse causality, we repeatedly analyzed both OS and DSS after excluding the 146 patients who died within the 1 year after surgery. We also examined the U-shaped relationships between BMI and survival through smoothing splines analysis using a B-spline basis [26]. The splines analysis was conducted with the multivariable model adjusting significant factors including age, sex, current smoker, family history of gastric cancer, operation, tumor histology, TNM stage, location, and ASA score. $P$ values $<0.05$ were considered statistically significant. All statistical analyses were performed using SAS software, version 9.4 (SAS Institute Inc., Cary, NC, USA.) and R software, version 3.3.3 (R Project for Statistical Computing).

\section{Results}

\section{Baseline characteristics}

Of the 7765 patients included in this study, 5153 (66.4\%) were male and $2612(33.6 \%)$ were female. Table 1 presents the baseline characteristics classified by BMI. The percentage of men was higher than that of women in all BMI groups, and the percentage of women was higher in the severely obese group than in other groups. As BMI increased, the proportion of current smokers tended to decrease; the current smoker rate was highest in underweight patients. The proportion of patients drinking alcohol was lower in underweight and severely obese patients than in other groups. As BMI increased, the proportion of patients undergoing subtotal gastrectomy tended to increase, while that of total gastrectomy tended to decrease.

TNM stage was more advanced and tumor size was larger in underweight patients than in normal and overweight groups. Accordingly, underweight patients were more likely to receive adjuvant chemotherapy. Patients with stage Ia cancer were more common in overweight and obese groups compared with patients who were normal weight or underweight. Underweight patients were likely to have upper third cancers or extended tumors.

An ASA score $\geq 3$ was most common in underweight patients and least common in overweight patients. The complication rate was highest in the underweight group.

\section{Survival analyses of overall and disease-specific survival}

Of the 7765 patients, 1279 (16.5\%) died, and 763 (9.8\%) deaths were due to gastric cancer. OS and DSS rates were significantly lower in the underweight group (log-rank $P<0.001$ for both OS and DSS). OS and DSS rates generally increased as BMI increased during long-term follow-up (Fig. 2).

Cox proportional hazards model (Table 2) showed that underweight patients had the worst OS, and patients who were overweight, mildly obese, and moderately obese groups had better OS. Severely obese patients had the best OS compared with normal-weight patients. In multivariable analysis adjusting for age, sex, and TNM stage, survival results were similar to the univariable results, although the association for OS in severely obese patients was attenuated and no longer statistically significant. When additionally adjusting for smoking, family history of gastric cancer, operation, histology, location, and ASA score, mildly obese patients had the best OS (this was statistically significant, with an HR 0.77 and $95 \%$ CI $0.66-0.90$ ), and the association between the moderately obese group and OS was no longer significant.

DSS results according to BMI groups were similar to the results for OS. However, the lowest HR was observed in the moderately obese group in both the age, sex, and TNM stage-adjusted model (HR 0.56; 95\% CI 0.38-0.83) and the age, TNM stage, operation, histology, and tumor locationadjusted model (HR 0.58; 95\% CI 0.39-0.85).

From the spline function analysis, a bell-shaped curve was shown and the HR for all-cause death was the lowest (HR 0.88; 95\% CI 0.81-0.95) at a BMI of 26.67 (Fig. 3).

\section{Subgroup analysis}

In subgroup analyses, according to TNM stage, univariable and multivariable models adjusting for age and sex were considered. The relationships between BMI and survival showed a non-linear pattern and similar trends to those noted in the whole group. The underweight group had the highest mortality in most subgroups.

As TNM stage increased, the lowest risk of death changed from patients who were overweight to those who were obese (Table 3). In stage Ia, HRs for OS in the overweight (HR $0.67 ; 95 \%$ CI $0.50-0.89$ ) and mildly obese (HR 0.74; $95 \%$ CI 0.55-0.99) groups were significantly lower than in the normal group in the multivariable model. The best OS was observed in the mildly obese group in stage $\mathrm{Ib}$ (HR 0.55 ; 95\% CI $0.36-0.84)$ and stage II (HR $0.71 ; 95 \%$ CI 0.51-0.99). In stage III, the moderately obese group had the best OS (HR 0.54; 95\% CI 0.32-0.91). For DSS, the highest risk of mortality was in the underweight group in stage Ia (HR 2.82; 95\% CI 1.07-7.42) and stage III (HR 
Table 1 Baseline characteristics according to body mass index at diagnosis

\begin{tabular}{|c|c|c|c|c|c|c|c|c|}
\hline & $(N=7765)$ & $\begin{array}{l}\text { Underweight } \\
(<18.5) \\
(N=299)\end{array}$ & $\begin{array}{l}\text { Normal }(18.5 \\
\text { to }<23) \\
(N=2976)\end{array}$ & $\begin{array}{l}\text { Overweight }(23 \\
\text { to }<25) \\
(N=1949)\end{array}$ & $\begin{array}{l}\text { Mildly } \\
\text { obese }(25 \\
\text { to }<28) \\
(N=1848)\end{array}$ & $\begin{array}{l}\text { Moderately } \\
\text { obese }(28 \\
\text { to }<30) \\
(N=467)\end{array}$ & $\begin{array}{l}\text { Severely obese } \\
(\geq 30) \\
(N=226)\end{array}$ & $P$ value \\
\hline \multicolumn{9}{|l|}{ Age (years) } \\
\hline Mean \pm SD & $58.6 \pm 11.9$ & $59.4 \pm 14.4$ & $58.3 \pm 12.7$ & $58.9 \pm 11.3$ & $58.7 \pm 11.1$ & $58.4 \pm 10.9$ & $57.0 \pm 11.1$ & 0.136 \\
\hline \multicolumn{9}{|l|}{ Sex } \\
\hline Male & $5153(66.4)$ & $192(64.2)$ & $1886(63.4)$ & 1356 (69.6) & $1287(69.6)$ & $307(65.7)$ & $125(55.3)$ & \multirow[t]{2}{*}{$<0.001$} \\
\hline Female & $2612(33.6)$ & $107(35.8)$ & 1090 (36.6) & $593(30.4)$ & $561(30.4)$ & $160(34.3)$ & $101(44.7)$ & \\
\hline \multicolumn{9}{|l|}{ Smoke } \\
\hline Never & 3166 (41.9) & $119(41.8)$ & $1258(43.3)$ & $761(40.3)$ & $724(40.0)$ & $189(41.8)$ & $115(52.8)$ & \multirow[t]{5}{*}{$<0.001$} \\
\hline $\begin{array}{r}\text { Former } \leq 30 \\
\text { pack-years }\end{array}$ & $1677(22.2)$ & 53 (18.6) & $572(19.7)$ & $451(23.9)$ & $458(25.3)$ & $104(23.0)$ & 39 (17.9) & \\
\hline $\begin{array}{r}\text { Former }>30 \\
\text { pack-years }\end{array}$ & $1068(14.1)$ & $30(10.5)$ & 403 (13.9) & $287(15.2)$ & $260(14.4)$ & $67(14.8)$ & $21(9.6)$ & \\
\hline $\begin{array}{r}\text { Current } \leq 30 \\
\text { pack-years }\end{array}$ & $910(12.0)$ & $42(14.7)$ & $350(12.0)$ & $227(12.0)$ & $205(11.3)$ & $56(12.4)$ & $30(13.8)$ & \\
\hline $\begin{array}{r}\text { Current }>30 \\
\text { pack-years }\end{array}$ & $742(9.8)$ & $41(14.4)$ & $324(11.2)$ & 163 (8.6) & $165(9.1)$ & $36(8.0)$ & $13(6.0)$ & \\
\hline \multicolumn{9}{|l|}{ Alcohol } \\
\hline No & $3378(44.3)$ & $150(51.9)$ & $1346(46.0)$ & 811 (42.6) & $766(42.0)$ & $198(43.5)$ & 107 (48.6) & \multirow[t]{2}{*}{0.003} \\
\hline Yes & 4239 (55.7) & $139(48.1)$ & $1579(54.0)$ & $1092(57.4)$ & $1059(58.0)$ & $257(56.5)$ & $113(51.4)$ & \\
\hline \multicolumn{9}{|c|}{ Family history of gastric cancer } \\
\hline No & $6077(78.3)$ & $240(80.3)$ & $2342(78.7)$ & $1549(79.5)$ & $1406(76.1)$ & $360(77.1)$ & $180(79.7)$ & \multirow[t]{2}{*}{0.130} \\
\hline Yes & $1688(21.7)$ & $59(19.7)$ & $634(21.3)$ & $400(20.5)$ & $442(23.9)$ & $107(22.9)$ & $46(20.3)$ & \\
\hline \multicolumn{9}{|l|}{ Operation } \\
\hline $\begin{array}{l}\text { Subtotal gas- } \\
\text { trectomy }\end{array}$ & $5534(71.3)$ & $185(61.9)$ & $2096(70.4)$ & $1399(71.8)$ & $1345(72.8)$ & $333(71.3)$ & $176(77.9)$ & \multirow[t]{3}{*}{$<0.001$} \\
\hline $\begin{array}{l}\text { Total gastrec- } \\
\text { tomy }\end{array}$ & $1865(24.0)$ & $105(35.1)$ & $752(25.3)$ & $442(22.7)$ & $415(22.5)$ & $107(22.9)$ & $44(19.5)$ & \\
\hline $\begin{array}{l}\text { Functional } \\
\text { gastrectomy }\end{array}$ & $366(4.7)$ & $9(3.0)$ & $128(4.3)$ & $108(5.5)$ & $88(4.8)$ & $27(5.8)$ & $6(2.6)$ & \\
\hline \multicolumn{9}{|l|}{ Histology } \\
\hline $\begin{array}{l}\text { Well-differen- } \\
\text { tiated }\end{array}$ & $1424(18.3)$ & $47(15.7)$ & $511(17.2)$ & $371(19.0)$ & $368(19.9)$ & $84(18.0)$ & $43(19.0)$ & \multirow[t]{6}{*}{0.003} \\
\hline $\begin{array}{l}\text { Moderate-dif- } \\
\text { ferentiated }\end{array}$ & $2191(28.2)$ & $89(29.8)$ & $786(26.4)$ & $551(28.3)$ & $553(29.9)$ & $140(30.0)$ & $72(31.9)$ & \\
\hline $\begin{array}{l}\text { Poor-differen- } \\
\text { tiated }\end{array}$ & $2106(27.1)$ & $85(28.4)$ & $866(29.1)$ & $538(27.6)$ & $433(23.4)$ & $126(27.0)$ & $58(25.7)$ & \\
\hline $\begin{array}{l}\text { Signet ring } \\
\text { cell }\end{array}$ & $1690(21.8)$ & $56(18.7)$ & $680(22.9)$ & 407 (20.9) & $407(22.0)$ & $92(19.7)$ & $48(21.2)$ & \\
\hline Mucinous & $184(2.4)$ & $14(4.7)$ & $75(2.5)$ & $35(1.8)$ & $48(2.6)$ & $10(2.1)$ & $2(0.9)$ & \\
\hline Papillary & $170(2.2)$ & $8(2.7)$ & $58(1.9)$ & $47(2.4)$ & $39(2.1)$ & $15(3.2)$ & $3(1.3)$ & \\
\hline \multicolumn{9}{|l|}{ Size $(\mathrm{cm})$} \\
\hline Mean \pm SD & $4.2 \pm 2.6$ & $5.4 \pm 3.4$ & $4.4 \pm 2.8$ & $4.0 \pm 2.5$ & $4.0 \pm 2.5$ & $4.0 \pm 2.3$ & $3.9 \pm 2.5$ & $<0.001$ \\
\hline \multicolumn{9}{|c|}{ Chemotherapy, adjuvant } \\
\hline No & $5977(77.0)$ & $203(67.9)$ & $2244(75.4)$ & $1539(79.0)$ & $1463(79.2)$ & $357(76.5)$ & $171(75.7)$ & \multirow[t]{2}{*}{$<0.001$} \\
\hline Yes & $1788(23.0)$ & $96(32.1)$ & $732(24.6)$ & $410(21.0)$ & $385(20.8)$ & $110(23.5)$ & $55(24.3)$ & \\
\hline \multicolumn{9}{|l|}{ TNM stage } \\
\hline Ia & $4055(52.2)$ & $102(34.1)$ & $1471(49.4)$ & $1084(55.6)$ & $1011(54.7)$ & $250(53.5)$ & $137(60.6)$ & \multirow[t]{4}{*}{$<0.001$} \\
\hline $\mathrm{Ib}$ & $1288(16.6)$ & $53(17.7)$ & $484(16.3)$ & $323(16.6)$ & $318(17.2)$ & $82(17.6)$ & $28(12.4)$ & \\
\hline II & $1278(16.5)$ & $59(19.7)$ & $517(17.4)$ & $294(15.1)$ & $293(15.9)$ & $80(17.1)$ & $35(15.5)$ & \\
\hline III & $1144(14.7)$ & $85(28.4)$ & $504(16.9)$ & $248(12.7)$ & $226(12.2)$ & $55(11.8)$ & $26(11.5)$ & \\
\hline
\end{tabular}


Table 1 (continued)

\begin{tabular}{|c|c|c|c|c|c|c|c|c|}
\hline & $(N=7765)$ & $\begin{array}{l}\text { Underweight } \\
(<18.5) \\
(N=299)\end{array}$ & $\begin{array}{l}\text { Normal }(18.5 \\
\text { to }<23) \\
(N=2976)\end{array}$ & $\begin{array}{l}\text { Overweight }(23 \\
\text { to }<25) \\
(N=1949)\end{array}$ & $\begin{array}{l}\text { Mildly } \\
\text { obese }(25 \\
\text { to }<28) \\
(N=1848)\end{array}$ & $\begin{array}{l}\text { Moderately } \\
\text { obese }(28 \\
\text { to }<30) \\
(N=467)\end{array}$ & $\begin{array}{l}\text { Severely obese } \\
(\geq 30) \\
(N=226)\end{array}$ & $P$ value \\
\hline \multicolumn{9}{|l|}{$\mathrm{T}$ stage } \\
\hline 1 & 4569 (58.8) & $119(39.8)$ & $1634(54.9)$ & $1215(62.3)$ & $1163(62.9)$ & $283(60.6)$ & 155 (68.6) & \multirow[t]{4}{*}{$<0.001$} \\
\hline 2 & 1029 (13.3) & $41(13.7)$ & $396(13.3)$ & $248(12.7)$ & $250(13.5)$ & $69(14.8)$ & $25(11.1)$ & \\
\hline 3 & 1374 (17.7) & $70(23.4)$ & $586(19.7)$ & 309 (15.9) & $301(16.3)$ & 79 (16.9) & $29(12.8)$ & \\
\hline 4 & $793(10.2)$ & $69(23.1)$ & $360(12.1)$ & $177(9.1)$ & $134(7.3)$ & $36(7.7)$ & $17(7.5)$ & \\
\hline \multicolumn{9}{|l|}{$\mathrm{N}$ stage } \\
\hline 0 & 5257 (67.7) & $162(54.2)$ & $1971(66.2)$ & $1378(70.7)$ & $1265(68.5)$ & $321(68.7)$ & $160(70.8)$ & \multirow[t]{4}{*}{$<0.001$} \\
\hline 1 & 1035 (13.3) & $43(14.4)$ & $392(13.2)$ & $232(11.9)$ & $260(14.1)$ & 79 (16.9) & $29(12.8)$ & \\
\hline 2 & $775(10.0)$ & 35 (11.7) & $307(10.3)$ & $199(10.2)$ & 179 (9.7) & $35(7.5)$ & $20(8.9)$ & \\
\hline 3 & $698(9.0)$ & $59(19.7)$ & $306(10.3)$ & $140(7.2)$ & $144(7.8)$ & $32(6.9)$ & $17(7.5)$ & \\
\hline \multicolumn{9}{|l|}{ Location } \\
\hline Upper & 1305 (16.8) & $58(19.4)$ & $516(17.3)$ & $312(16.0)$ & $300(16.2)$ & 84 (18.0) & 35 (15.5) & \multirow[t]{4}{*}{0.014} \\
\hline Middle & $2870(37.0)$ & $97(32.4)$ & $1096(36.8)$ & 754 (38.7) & $674(36.5)$ & $164(35.1)$ & 85 (37.6) & \\
\hline Lower & $3520(45.3)$ & $135(45.2)$ & $1332(44.8)$ & $871(44.7)$ & $862(46.7)$ & $214(45.8)$ & $106(46.9)$ & \\
\hline Extended & $70(0.9)$ & $9(3.0)$ & $32(1.1)$ & $12(0.6)$ & $12(0.6)$ & $5(1.1)$ & $0(0.0)$ & \\
\hline \multicolumn{9}{|l|}{ ASA score } \\
\hline 1 & $2664(34.3)$ & $105(35.1)$ & $1155(38.8)$ & $672(34.5)$ & $566(30.6)$ & $117(25.0)$ & 49 (21.7) & \multirow[t]{3}{*}{$<0.001$} \\
\hline 2 & $4821(62.1)$ & $178(59.5)$ & $1702(57.2)$ & $1223(62.7)$ & $1218(65.9)$ & $330(70.7)$ & $170(75.2)$ & \\
\hline$\geq 3$ & $280(3.6)$ & $16(5.4)$ & $119(4.0)$ & $54(2.8)$ & $64(3.5)$ & $20(4.3)$ & $7(3.1)$ & \\
\hline \multicolumn{9}{|c|}{ Complication } \\
\hline No & $6509(83.8)$ & $231(77.3)$ & $2536(85.2)$ & $1645(84.4)$ & $1536(83.1)$ & $376(80.5)$ & 185 (81.9) & \multirow[t]{2}{*}{0.002} \\
\hline Yes & $1256(16.2)$ & $68(22.7)$ & $440(14.8)$ & $304(15.6)$ & $312(16.9)$ & $91(19.5)$ & $41(18.1)$ & \\
\hline
\end{tabular}

ASA American Society of Anesthesiologists, $M$ stage metastasis stage, $N$ stage node stage, $S D$ standard deviation, $T$ stage tumor stage, $T N M$ tumor-node-metastasis
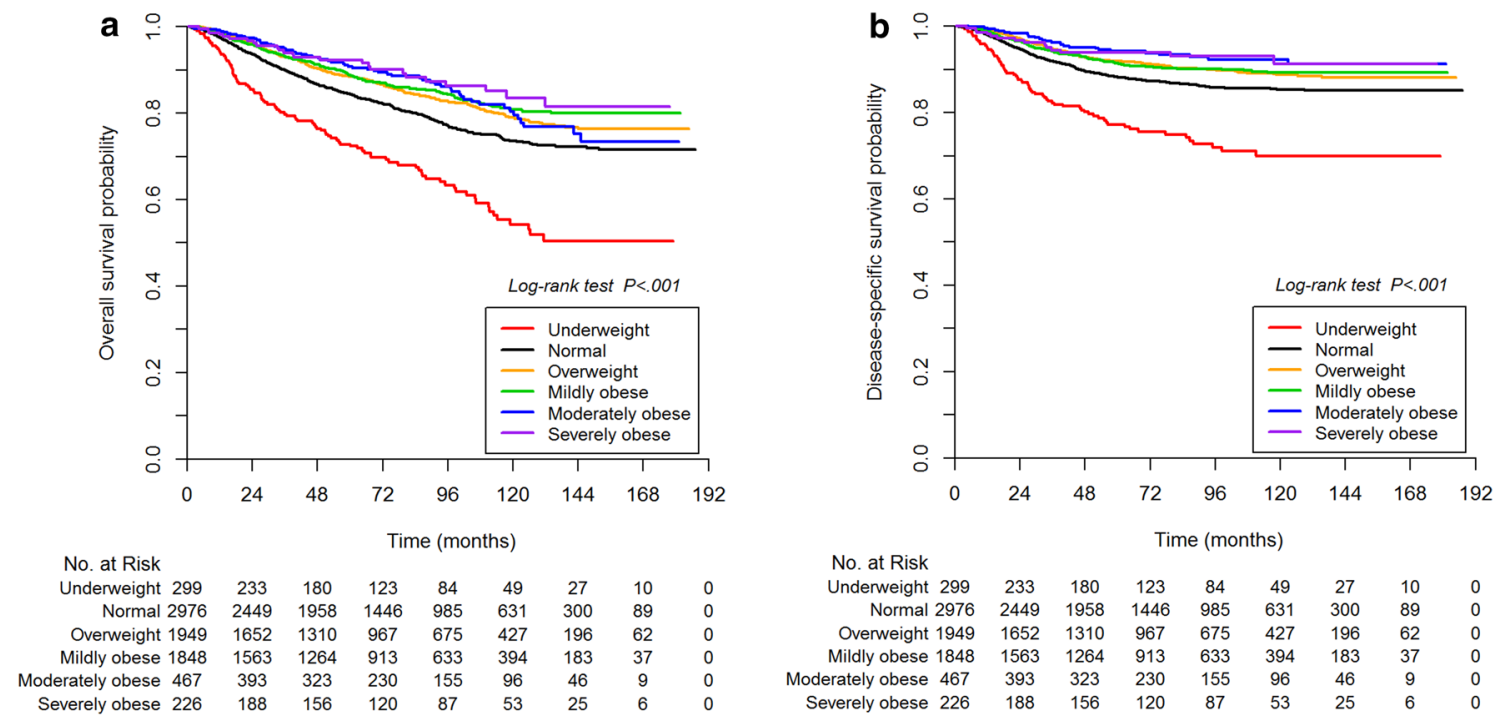

Fig. 2 Kaplan-Meier curves according to body mass index at diagnosis for a overall survival and $\mathbf{b}$ disease-specific survival 
Table 2 Hazard ratios for body mass index at diagnosis obtained using Cox proportional hazard models

\begin{tabular}{|c|c|c|c|c|c|c|c|c|c|}
\hline \multirow[t]{2}{*}{ BMI category } & & \multirow{2}{*}{$\begin{array}{l}\text { Patients } \\
\text { No. }\end{array}$} & \multirow{2}{*}{$\begin{array}{l}\text { Events } \\
\text { No. }^{\mathrm{a}}\end{array}$} & \multicolumn{2}{|l|}{ Univariable model } & \multicolumn{2}{|c|}{ Multivariable model $1^{\mathrm{b}}$} & \multicolumn{2}{|c|}{ Multivariable model $2^{\mathrm{c}, \mathrm{d}}$} \\
\hline & & & & HR $(95 \%$ CI $)$ & $P$ value & HR $(95 \%$ CI $)$ & $P$ value & HR $(95 \%$ CI $)$ & $P$ value \\
\hline \multicolumn{10}{|l|}{ Overall survival } \\
\hline Total & & 7765 & $1279(16.5)$ & & & & & & \\
\hline Normal & $(18.5$ to $<23)$ & 2976 & $564(19.0)$ & 1 (ref) & $(<0.001)$ & 1 (ref) & $(<0.001)$ & 1 (ref) & $(<0.001)$ \\
\hline Underweight & $(<18.5)$ & 299 & $102(34.1)$ & $1.97(1.59-2.43)$ & $<0.001$ & $1.48(1.20-1.83)$ & $<0.001$ & $1.42(1.15-1.77)$ & 0.002 \\
\hline Overweight & $(23$ to $<25)$ & 1949 & $284(14.6)$ & $0.75(0.65-0.87)$ & $<0.001$ & $0.81(0.71-0.94)$ & 0.005 & $0.84(0.73-0.97)$ & 0.018 \\
\hline Mildly obese & $(25$ to $<28)$ & 1848 & $243(13.2)$ & $0.68(0.59-0.79)$ & $<0.001$ & $0.75(0.64-0.87)$ & $<0.001$ & $0.77(0.66-0.90)$ & 0.001 \\
\hline $\begin{array}{l}\text { Moderately } \\
\text { obese }\end{array}$ & $(28$ to $<30)$ & 467 & $61(13.1)$ & $0.68(0.52-0.88)$ & 0.004 & $0.75(0.57-0.98)$ & 0.032 & $0.77(0.59-1.01)$ & 0.060 \\
\hline Severely obese & $(\geq 30)$ & 226 & $25(11.1)$ & $0.56(0.38-0.84)$ & 0.005 & $0.75(0.50-1.12)$ & 0.156 & $0.77(0.51-1.15)$ & 0.205 \\
\hline \multicolumn{10}{|c|}{ Disease-specific survival } \\
\hline Total & & 7765 & $763(9.8)$ & & & & & & \\
\hline Normal & $(18.5$ to $<23)$ & 2976 & $339(11.4)$ & 1 (ref) & $(<0.001)$ & 1 (ref) & $(<0.001)$ & 1 (ref) & $(<0.001)$ \\
\hline Underweight & $(<18.5)$ & 299 & $70(23.4)$ & $2.19(1.70-2.84)$ & $<0.001$ & $1.50(1.16-1.94)$ & 0.002 & $1.48(1.14-1.92)$ & 0.003 \\
\hline Overweight & $(23$ to $<25)$ & 1949 & $161(8.3)$ & $0.71(0.59-0.85)$ & $<0.001$ & $0.81(0.67-0.98)$ & 0.030 & $0.84(0.70-1.01)$ & 0.068 \\
\hline Mildly obese & $(25$ to $<28)$ & 1848 & $152(8.2)$ & $0.71(0.58-0.86)$ & $<0.001$ & $0.83(0.68-1.00)$ & 0.052 & $0.84(0.70-1.02)$ & 0.082 \\
\hline $\begin{array}{l}\text { Moderately } \\
\text { obese }\end{array}$ & $(28$ to $<30)$ & 467 & $27(5.8)$ & $0.50(0.34-0.74)$ & 0.001 & $0.56(0.38-0.83)$ & 0.004 & $0.58(0.39-0.85)$ & 0.006 \\
\hline Severely obese & $(\geq 30)$ & 226 & $14(6.2)$ & $0.53(0.31-0.91)$ & 0.021 & $0.72(0.42-1.22)$ & 0.220 & $0.75(0.44-1.27)$ & \\
\hline
\end{tabular}

$B M I$ body mass index, $C I$ confidence interval, $H R$ hazard ratio, $N o$. number, ref reference, $T N M$ tumor-node-metastasis

${ }^{a}$ An event indicates a death, either overall or disease-specific

${ }^{\mathrm{b}}$ Age, sex, and TNM stage were adjusted for in multivariable model 1 for overall survival and disease-specific survival

${ }^{\mathrm{c}}$ Age, sex, current smoker, family history of gastric cancer, operation, histology, TNM stage, location, and American Society of Anesthesiologists score were adjusted for in multivariable model 2 for overall survival

${ }^{\mathrm{d}}$ Age, operation, histology, TNM stage, and location were adjusted for in multivariable model 2 for disease-specific survival

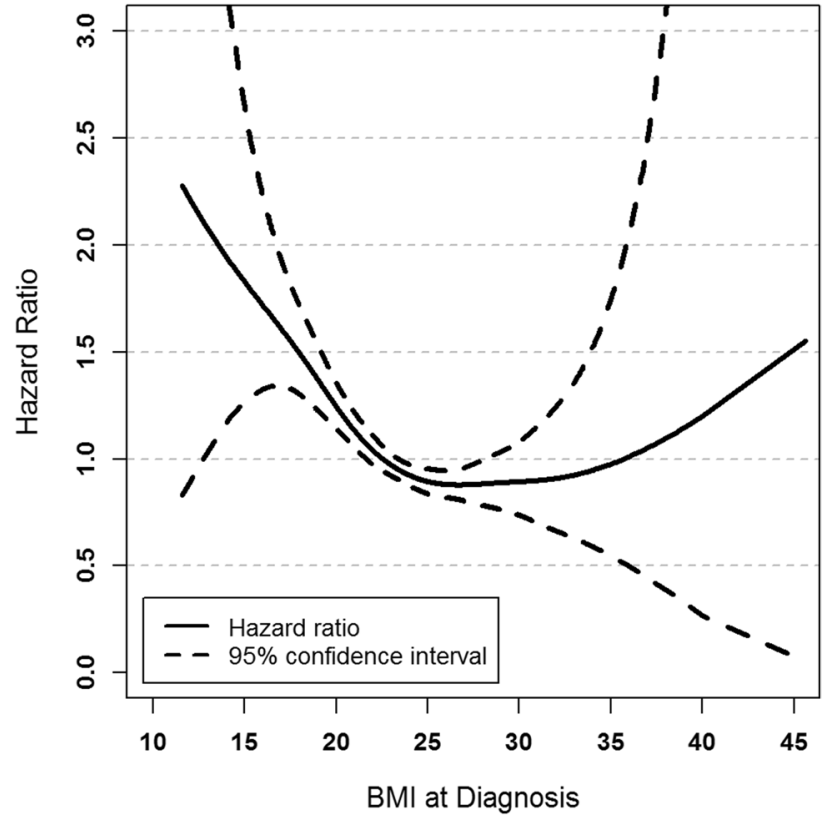

Fig. 3 Body mass index (BMI) at diagnosis and overall survival. Age, sex, current smoker, family history of gastric cancer, operation, histology, TNM stage, location, and American Society of Anesthesiologists score were adjusted
$1.42 ; 95 \%$ CI $1.02-1.98)$. The best DSS was observed in the mildly obese group in stage Ib patients (HR $0.50 ; 95 \%$ CI $0.25-0.99$ ), the overweight group in stage II patients (HR 0.68 ; $95 \%$ CI $0.47-0.99$ ), and the moderately obese group in stage III patients (HR 0.46; 95\% CI 0.25-0.84). Therefore, as stage increased, the importance of weight on mortality seemed to increase. In early stage disease, underweight did not seem to have a large effect on OS; it had a greater effect on DSS.

In subgroup analysis of age stratified by three subgroups separated by cut-off points at 40 and 65 years, BMI was not associated with survival in the $<40$ year subgroup (Supplementary Table 1). The effect of being underweight became prominent in patients over 40 . In the $\geq 40$ to $<65$ years subgroup, DSS was the best for moderately obese patients (HR 0.47 ; $95 \%$ CI $0.25-0.89)$. In $>65$ years patients, OS was the best in the mildly obese group (HR 0.63; 95\% CI 0.51-0.78), and DSS was the best in the mildly obese group (HR 0.73; 95\% CI 0.55-0.96) and overweight group (HR 0.71; 95\% CI 0.54-0.94).

For patients undergoing subtotal gastrectomy (Supplementary Table 2), overweight patients had the best OS (HR 0.76; 95\% CI 0.32-0.91) and DSS (HR 0.76; 95\% CI 


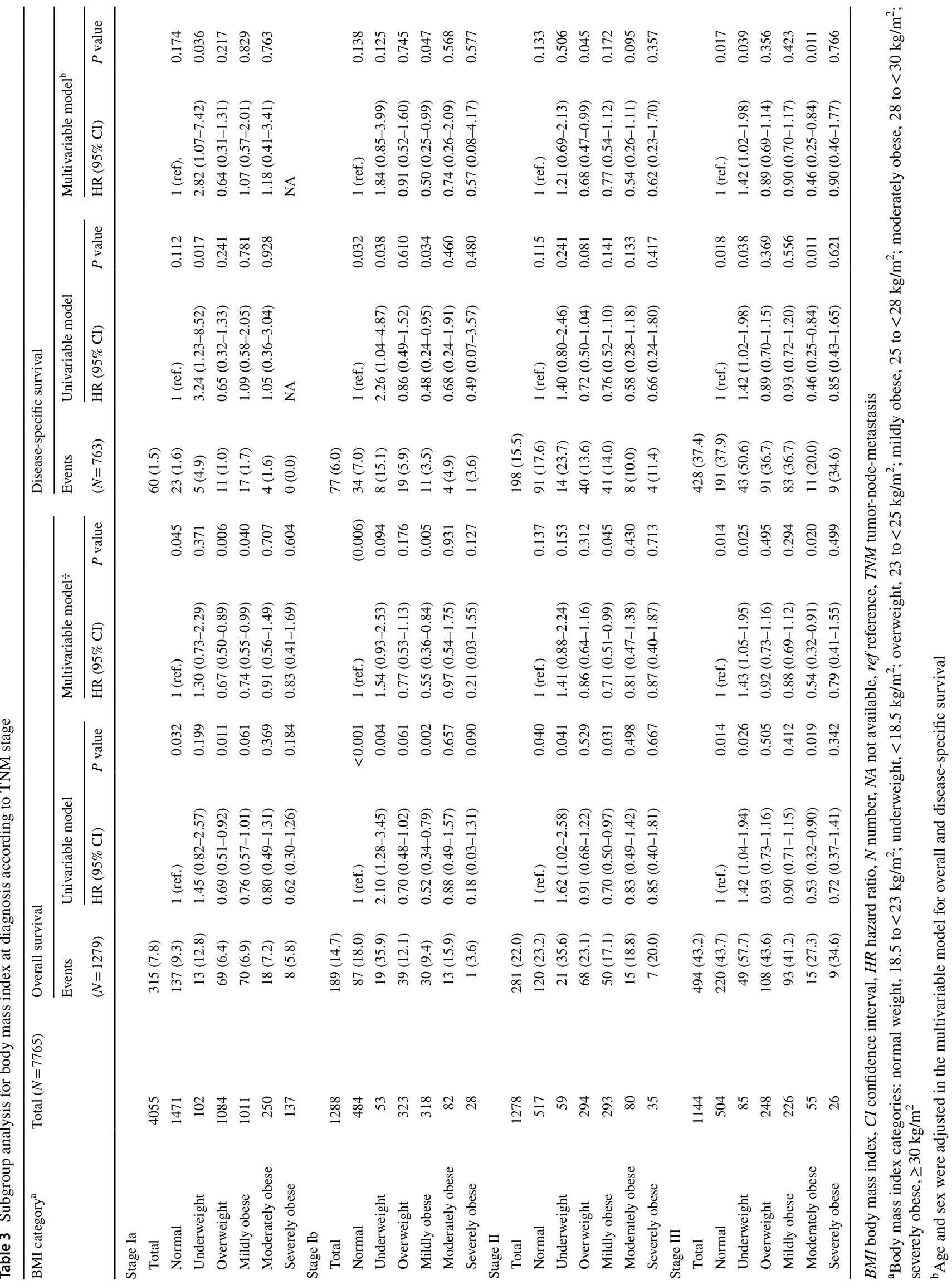


0.59-0.96). Mildly obese patients had only significantly better OS compared with normal-weight patients (HR 0.81; 95\% CI 0.67-0.97). OS and DSS were similar for underweight and normal-weight patients in multivariable models. For those undergoing total gastrectomy, underweight patients had the worst prognosis for both OS (HR 1.64; 95\% CI 1.21-2.22) and DSS (HR 1.86; 95\% CI 1.30-2.67). Obese patients exhibited a better survival than normal or underweight patients. Particularly, moderately obese patients had the lowest HR for both OS (HR 0.51; 95\% CI 0.30-0.87) and DSS (HR 0.36; 95\% CI 0.16-0.82), compared with normalweight or overweight patients. No trends according to BMI were observed in the functional gastrectomy subgroup. Our findings suggest that being underweight adversely affects outcomes in patients undergoing total gastrectomy but not subtotal gastrectomy. BMI was more important for survival in patients undergoing total gastrectomy than those undergoing subtotal gastrectomy.

When BMI was measured 1-year post-operatively, obese patients tended to have a lower risk of mortality (Supplementary Table 3), which was similar to the pattern of associations observed for BMI at diagnosis. Underweight patients had worse OS (HR 2.54; 95\% CI 1.70-3.79) and DSS (HR 2.74; 95\% CI 1.72-4.36). OS (HR 0.35; 95\% CI 0.15-0.85) and DSS (HR 0.23; 95\% CI 0.07-0.70) were best in mildly obese patients. The overweight group also exhibited significantly better DSS (HR 0.52; 95\% CI 0.28-0.98) than normal-weight patients.

Considering changes in BMI after 1 year, overweight or obese patients exhibited better prognosis than normal-weight or underweight groups, regardless of changes in BMI. Patients with change of BMI of $>10 \%$ had worse overall (HR 1.44; 95\% CI 1.08-1.93) and disease-specific survival (HR 1.61; 95\% CI 1.14-2.26) than those with change of BMI of $\leq 10 \%$. We also did multivariate analyses according to BMI at diagnosis. Most BMI groups with change of BMI of $>10 \%$ tended to have worse overall and disease-specific survival than those with $\leq 10 \%$. However, small sample and event numbers caused by cellularized groups may lead to statistically insignificant results (Supplementary Table 4).

Both OS and DSS were no major changes in the Cox proportional hazard model and subgroup analysis results when the analyses were repeated excluding the 146 patients who died in the first year post-gastrectomy. The risk of death in underweight patients was somewhat reduced when excluding these early deaths (data not shown).

\section{Discussion}

In this large cohort study, patients who were overweight or obese at diagnosis had better OS and DSS than those who were normal-weight or underweight. When subgroup analyses were performed according to tumor stage, this pattern was maintained in all stage groups. Even in stage Ia, the best OS was observed in the overweight group. A similar pattern was found during subgroup analysis when patients were classified according to age or operation method, except in the $<40$-year age group and patients who underwent functional preserving gastrectomy. The lack of an association between BMI and survival in these two exceptions may be caused by the relatively small size of these subgroups. Interestingly, the influence of weight on patient mortality increased, as tumor stage or gastric resection increased, such as in case of total gastrectomy. Under these conditions, weight loss is more likely to occur rather compared with less advanced tumor stage or subtotal gastrectomy. The non-linear pattern of association between BMI and survival was observed even when BMI was measured 1 year after gastrectomy. When we excluded deaths within 1 year after surgery because of possible reverse causality, in which the cancer may have already progressed in underweight patients, the same pattern was observed.

The previous studies investigating the effect of BMI on gastric cancer have produced conflicting results. Some studies suggested that BMI at diagnosis did not affect mortality in patients undergoing resection for gastric cancer [27-32]. Other studies reported that obese patients at the time of diagnosis had better long-term survival [15, 16, 33]. However, those studies had small sample sizes or were confined to specific groups. Furthermore, patients were categorized into only two or three BMI groups because of the small sample size. The current study included a larger cohort than the previous gastric cancer studies and followed the patients for a prolonged period. We also considered many variables that could affect OS and DSS, leading to comprehensive analyses. Our results were consistent with those of previous studies comparing at-diagnosis BMI vs. post-operative BMI [31] and early vs. advanced gastric cancers [28, 29]. The current study confirmed the obesity paradox in gastric cancer.

At a BMI of less than 18.5, hazard ratios for all-cause death were significantly increased in general population of both Western and Asians [34, 35]. Our result that underweight patients who underwent gastric resection were associated with worse survival is consistent with finding general population.

In this study, we attempted to correct biases found in other studies about BMI affecting survival. First, cancer incidence is a collider variable, because it is generally caused by both obesity and other risk factors. We tried to include all variables influencing survival, and we minimized surgical confounding factors by limiting enrollment to patients who underwent curative resection from our well-designed cohorts. Second, detection bias may occur if two diagnoses coexisted [36]. To minimize this bias, we also adjusted for possible confounding variables in all analyses. 
The non-linear pattern was not observed in patients $<40$ years for both OS and DSS, whereas those 40-65 years and $>65$ years exhibited the non-linear relationship between BMI and survival. This suggests that the prognosis of younger patients may be less likely to be affected by body weight than older patients. However, the lack of association may also reflect the small sample size and number of events in the $<40$-year subgroup, prohibiting the demonstration of statistically significant results.

Several reasons have been suggested for why patients with obesity exhibit a better prognosis in gastric cancer. One explanation is tumor biology: obese patients tend to have a less aggressive type of cancer. Obese patients with endometrial and renal cell cancers were reported to have predominantly subtypes with a good prognosis [10, 37]. In gastric cancer, overweight patients were less likely to have aggressive tumors [33]. Visceral obesity was significantly associated with decreased lymph node metastasis in colorectal cancer [38]. Our results likewise showed that advanced stage cancer was less common in patients with a high BMI. Conversely, obesity has been reported to promote peritoneal dissemination of gastric cancer [30, 39]. Further investigation is required to clarify this issue. A second reason is that weight loss can occur after gastrectomy. Overweight or obese patients may achieve ideal body weight, resulting in better long-term prognosis after gastrectomy [33]. This is supported by our results showing the worst outcomes in underweight patients and the best survival in moderately obese patients undergoing total gastrectomy, as well as the best outcomes in overweight patients undergoing subtotal gastrectomy. A previous study reported that patients who underwent gastrectomy had reduced cardiovascular mortality because of significantly reduced body weight and visceral fat post-operatively [40]. Gastrectomy causes weight loss because of decreased gastric volume and hormonal changes [41]. Patients undergoing gastrectomy commonly have impaired production of ghrelin, which stimulates secretion of growth hormones, increases food intake, and causes weight gain [42-44]. A third explanation is that excess adipose tissue serves as a nutrient reserve and confers a survival advantage in times of stress, such as during anti-cancer treatment [45]. Especially after gastrectomy, patients are prone to malnutrition because of esophagitis, dumping syndrome, or gastric stasis.

There are several limitations to our study. First, our study did not consider physical activity or BMI at least 6 months before diagnosis as covariates, both of which may have affected BMI at diagnosis. However, other factors that can affect BMI, including tumor stage, smoking, family history, and adjuvant chemotherapy, were adjusted for. Second, lean body mass was not evaluated when BMI was checked. Because low muscle mass in advanced cancer is common and is known to be an independent predictor of immobility and mortality [46], sarcopenia may be more helpful prognostic factor rather than BMI to predict post-operative outcome in gastric cancer patients. Third, and most importantly, although low BMI was a poor prognostic factor in the present study, gastric cancer itself can cause weight loss- the so-called "reverse causality" [47]. In general, gastric cancer patients with weight loss tend to have an advanced tumor stage [48, 49], which is the strongest prognostic factor for gastric cancer. To minimize this phenomenon, we performed subgroup analysis according to tumor stage and the similar pattern-high mortality in underweight patients and low mortality in overweight or obese patients-was observed even in patients with stage Ia and Ib tumors. In addition, we repeated our analyses excluding patients who died within 1 year after surgery. The previous studies of endometrial cancer showed that the extent of weight loss correlated with the initial BMI, such that heavier patients lost more body weight than lighter patients [50], and post-diagnosis BMI was less likely to influence survival than pre-diagnosis BMI [51]. However, that study included only early stage tumors. When we compared patients with severe weight loss (weight change $>10 \%$ ) and those with mild weight loss or no change (weight change $\leq 10 \%$ ) at 1 year after surgery, both OS and DSS were significantly different. Further study is necessary to evaluate associations between post-operative weight change and survival. Of note, as cancer stage increased, the lowest risk of death changed from overweight to obese patients, suggesting that the importance of nutrition increases with stage in patients with gastric cancer. Similar pattern was observed, as the extent of gastric resection increased. Therefore, significance of nutrition should be emphasized to weight loss - anticipated patients, especially patients with advanced tumor stage or those undergoing total gastrectomy.

Our study demonstrated that overweight and mildly obese status are good prognostic factors for both OS and DSS in patients with gastric cancer undergoing curative gastrectomy. These conclusions emphasize the risks of weight loss before and after surgery and remind the importance of nutrition in patients with gastric cancer. Our study also showed that patients with large change of BMI at 1 year after surgery tended to have worse OS and DSS than those with small change of BMI. This suggests that nutritional support after gastric resection may improve patients' outcome. A randomized study of intensive nutritional support after gastric resection may reveal if it improves patients' short- and longterm outcomes.

Acknowledgements This study was supported by Grants from the National Cancer Center, Korea (\#1610160-2) and the National Research Foundation (\#NRF-2016R1A2B1010377).

Author contributions JHL contributed to data acquisition, analysis and interpretation of data, and drafting of the manuscript; BP contributed 
to statistical analysis, interpretation of data, and drafting of the manuscript; JJ contributed to statistical analysis, interpretation of data and administrative support; M-CK contributed to pathological analysis and interpretation of data; Y-IK contributed to critical revision of the manuscript for important intellectual content; JYL contributed to critical revision of the manuscript for important intellectual content; CGK contributed to critical revision of the manuscript for important intellectual content; IJC contributed to critical revision of the manuscript for important intellectual content; BWE contributed to critical revision of the manuscript for important intellectual content; HMY contributed to critical revision of the manuscript for important intellectual content; KWR contributed to critical revision of the manuscript for important intellectual content; Y-WK contributed to critical revision of the manuscript for important intellectual content; S-JC contributed to study concept and design, analysis and interpretation of data, drafting of the manuscript, obtained funding, and study supervision.

\section{Compliance of ethical standards}

Conflicts of interest The authors declare that there are no conflicts of interest.

Human rights statement and informed consent All procedures followed were in accordance with the ethical standards of the responsible committee on human experimentation (institutional and national) and with the Helsinki Declaration of 1964 and later versions. Informed consent or a substitute for it was obtained from all patients for being included in the study.

\section{References}

1. Ferlay J, Soerjomataram I, Dikshit R, et al. Cancer incidence and mortality worldwide: sources, methods and major patterns in GLOBOCAN 2012. Int J Cancer. 2015;136:E359-86.

2. Ahn HS, Lee HJ, Yoo MW, et al. Changes in clinicopathological features and survival after gastrectomy for gastric cancer over a 20-year period. Br J Surg. 2011;98:255-60.

3. Calle EE, Rodriguez C, Walker-Thurmond K, et al. Overweight, obesity, and mortality from cancer in a prospectively studied cohort of US adults. N Engl J Med. 2003;348:1625-38.

4. Crosbie EJ, Zwahlen M, Kitchener HC, et al. Body mass index, hormone replacement therapy, and endometrial cancer risk: a meta-analysis. Cancer Epidemiol Biomark Prev. 2010;19:3119-30.

5. Renehan AG, Tyson M, Egger M, et al. Body-mass index and incidence of cancer: a systematic review and meta-analysis of prospective observational studies. Lancet. 2008;371:569-78.

6. Yang P, Zhou Y, Chen B, et al. Overweight, obesity and gastric cancer risk: results from a meta-analysis of cohort studies. Eur $\mathbf{J}$ Cancer. 2009;45:2867-73.

7. Merry AH, Schouten LJ, Goldbohm RA, et al. Body mass index, height and risk of adenocarcinoma of the oesophagus and gastric cardia: a prospective cohort study. Gut. 2007;56:1503-11.

8. Chen Y, Liu L, Wang X, et al. Body mass index and risk of gastric cancer: a meta-analysis of a population with more than ten million from 24 prospective studies. Cancer Epidemiol Biomark Prev. 2013;22:1395-408.

9. O'Doherty MG, Freedman ND, Hollenbeck AR, et al. A prospective cohort study of obesity and risk of oesophageal and gastric adenocarcinoma in the NIH-AARP Diet and Health Study. Gut. 2012;61:1261-8.
10. Hakimi AA, Furberg H, Zabor EC, et al. An epidemiologic and genomic investigation into the obesity paradox in renal cell carcinoma. J Natl Cancer Inst. 2013;105:1862-70.

11. Parker AS, Lohse CM, Cheville JC, et al. Greater body mass index is associated with better pathologic features and improved outcome among patients treated surgically for clear cell renal cell carcinoma. Urology. 2006;68:741-6.

12. Kroenke $\mathrm{CH}$, Neugebauer R, Meyerhardt J, et al. Analysis of body mass index and mortality in patients with colorectal cancer using causal diagrams. JAMA Oncol. 2016;2:1137-45.

13. Schlesinger S, Siegert S, Koch M, et al. Postdiagnosis body mass index and risk of mortality in colorectal cancer survivors: a prospective study and meta-analysis. Cancer Causes Control. 2014;25:1407-18.

14. Hines RB, Shanmugam C, Waterbor JW, et al. Effect of comorbidity and body mass index on the survival of AfricanAmerican and Caucasian patients with colon cancer. Cancer. 2009;115:5798-806.

15. Tokunaga M, Hiki N, Fukunaga T, et al. Better 5-year survival rate following curative gastrectomy in overweight patients. Ann Surg Oncol. 2009;16:3245-51.

16. Chen HN, Chen XZ, Zhang WH, et al. The impact of body mass index on the surgical outcomes of patients with gastric cancer: a 10-year, single-institution cohort study. Medicine (Baltimore). 2015;94:e1769.

17. Consultation WHOE. Appropriate body-mass index for Asian populations and its implications for policy and intervention strategies. Lancet. 2004;363:157-63.

18. Wee HL, Cheung YB, Loke WC, et al. The association of body mass index with health-related quality of life: an exploratory study in a multiethnic Asian population. Value Health. 2008;11(Suppl 1):S105-14.

19. Davis JL, Selby LV, Chou JF, et al. Patterns and predictors of weight loss after gastrectomy for cancer. Ann Surg Oncol. 2016;23:1639-45.

20. Washington K. 7th edition of the AJCC cancer staging manual: stomach. Ann Surg Oncol. 2010;17:3077-9.

21. Daabiss M. American Society of Anaesthesiologists physical status classification. Indian J Anaesth. 2011;55:111-5.

22. Japanese Gastric Cancer. A. Japanese gastric cancer treatment guidelines 2014 (ver. 4). Gastric Cancer. 2017;20:1-19.

23. Park JY, Kim YW, Ryu KW, et al. Assessment of laparoscopic stomach preserving surgery with sentinel basin dissection versus standard gastrectomy with lymphadenectomy in early gastric cancer-A multicenter randomized phase III clinical trial (SENORITA trial) protocol. BMC Cancer. 2016;16:340.

24. Park JY, Kook MC, Eom BW, et al. Practical intraoperative pathologic evaluation of sentinel lymph nodes during sentinel node navigation surgery in gastric cancer patients-proposal of the pathologic protocol for the upcoming SENORITA trial. Surg Oncol. 2016;25:139-46.

25. Biondi A, Persiani R, Cananzi F, et al. R0 resection in the treatment of gastric cancer: room for improvement. World J Gastroenterol. 2010;16:3358-70.

26. Eilers PHC, Marx BD. Flexible smoothing with B-splines and penalties. Stat Sci. 1996;11:89-102.

27. Ejaz A, Spolverato G, Kim Y, et al. Impact of body mass index on perioperative outcomes and survival after resection for gastric cancer. J Surg Res. 2015;195:74-82.

28. Lin YS, Huang KH, Lan YT, et al. Impact of body mass index on postoperative outcome of advanced gastric cancer after curative surgery. J Gastrointest Surg. 2013;17:1382-91.

29. Kulig J, Sierzega M, Kolodziejczyk P, et al. Implications of overweight in gastric cancer: a multicenter study in a Western patient population. Eur J Surg Oncol. 2010;36:969-76. 
30. Ojima T, Iwahashi M, Nakamori M, et al. Influence of overweight on patients with gastric cancer after undergoing curative gastrectomy: an analysis of 689 consecutive cases managed by a single center. Arch Surg. 2009;144:351-8.

31. Lee HH, Park JM, Song KY, et al. Survival impact of postoperative body mass index in gastric cancer patients undergoing gastrectomy. Eur J Cancer. 2016;52:129-37.

32. Wu XS, Wu WG, Li ML, et al. Impact of being overweight on the surgical outcomes of patients with gastric cancer: a meta-analysis. World J Gastroenterol. 2013;19:4596-606.

33. Kong F, Li H, Fan Y, et al. Overweight patients achieve ideal body weight following curative gastrectomy resulting in better long-term prognosis. Obes Surg. 2013;23:650-6.

34. Jee SH, Sull JW, Park J, et al. Body-mass index and mortality in Korean men and women. N Engl J Med. 2006;355(8):779-87.

35. de Gonzalez AB, Hartge P, Cerhan JR, et al. Body mass index and mortality among 1.46 million white adults. N Engl J Med. 2010;363:2211-9.

36. Johnson JA, Bowker SL, Richardson K, et al. Time-varying incidence of cancer after the onset of type 2 diabetes: evidence of potential detection bias. Diabetologia. 2011;54:2263-71.

37. Arem H, Irwin ML. Obesity and endometrial cancer survival: a systematic review. Int J Obes (Lond). 2013;37:634-9.

38. Park SW, Lee HL, Ju YW, et al. Inverse association between visceral obesity and lymph node metastasis in gastric cancer. J Gastrointest Surg. 2015;19:242-50.

39. Chen S, Nie RC, OuYang LY, et al. Body mass index (BMI) may be a prognostic factor for gastric cancer with peritoneal dissemination. World J Surg Oncol. 2017;15:52.

40. Lee $\mathrm{YH}, \mathrm{Han} \mathrm{SJ}$, Kim HC, et al. Gastrectomy for early gastric cancer is associated with decreased cardiovascular mortality in association with postsurgical metabolic changes. Ann Surg Oncol. $2013 ; 20: 1250-7$

41. Liedman B, Andersson H, Bosaeus I, et al. Changes in body composition after gastrectomy: results of a controlled, prospective clinical trial. World J Surg. 1997;21:416-21.

42. Adachi S, Takiguchi S, Okada K, et al. Effects of ghrelin administration after total gastrectomy: a prospective, randomized, placebo-controlled phase II study. Gastroenterology. 2010;138:1312-20.

43. Ariyasu H, Takaya K, Tagami T, et al. Stomach is a major source of circulating ghrelin, and feeding state determines plasma ghrelin-like immunoreactivity levels in humans. J Clin Endocrinol Metab. 2001;86:4753-8.

44. Karamanakos SN, Vagenas K, Kalfarentzos F, et al. Weight loss, appetite suppression, and changes in fasting and postprandial ghrelin and peptide-YY levels after Roux-en-Y gastric bypass and sleeve gastrectomy: a prospective, double blind study. Ann Surg. 2008;247:401-7.

45. Gonzalez MC, Pastore CA, Orlandi SP, et al. Obesity paradox in cancer: new insights provided by body composition. Am J Clin Nutr. 2014;99:999-1005.

46. Prado CM, Lieffers JR, McCargar LJ, et al. Prevalence and clinical implications of sarcopenic obesity in patients with solid tumours of the respiratory and gastrointestinal tracts: a population-based study. Lancet Oncology. 2008;9:625-35.

47. Flegal KM, Graubard BI, Williamson DF, et al. Reverse causation and illness-related weight loss in observational studies of body weight and mortality. Am J Epidemiol. 2011;173:1-9.

48. Stephens MR, Lewis WG, White S, et al. Prognostic significance of alarm symptoms in patients with gastric cancer. Br J Surg. 2005;92:840-6.

49. Bowrey DJ, Griffin SM, Wayman J, et al. Use of alarm symptoms to select dyspeptics for endoscopy causes patients with curable esophagogastric cancer to be overlooked. Surg Endosc. 2006;20:1725-8.

50. Renehan AG, Crosbie EJ, Campbell PT. Re: Prediagnosis body mass index, physical activity, and mortality in endometrial cancer patients. J Natl Cancer Inst. 2014;106:djt375.

51. Crosbie EJ, Roberts C, Qian W, et al. Body mass index does not influence post-treatment survival in early stage endometrial cancer: results from the MRC ASTEC trial. Eur J Cancer. 2012;48:853-64. 